\title{
Salvage intraperitoneal chemotherapy for relapsed type II endometrial cancer: A pilot case-control study
}

\author{
Yi-Chen Tsai, ${ }^{1,2}$, Yen-Hou Chang ${ }^{1,2}$, Yi-Chang ${ }^{1,2}$, Chi-Mu Chuang ${ }^{1,2}$ \\ IInstitute of Clinical Medicine, National Yang-Ming University School of Medicine, Taipei, Taiwan \\ ${ }^{2}$ Section of Gynecologic Oncology, Department of Obstetrics and Gynecology, Taipei Veterans General Hospital, Taipei, Taiwan
}

\begin{abstract}
Objective: Epithelial ovarian cancer and relapsed type II endometrial cancer share common characteristics. Although the role of intraperitoneal (IP) chemotherapy in the treatment of epithelial ovarian cancer has been well-established, its role in the treatment of relapsed type II endometrial cancer remains to be elucidated.

Material and Methods: From January 2000 to December 2012, patients who were diagnosed with relapsed type II endometrial cancer and underwent secondary cytoreductive surgery, patients with residual tumors less than $1 \mathrm{~cm}$ in diameter were initially screened for this study. Of the screened patients, consecutive patients who received salvage IP chemotherapy (IP platinum plus intravenous paclitaxel) were considered the case group. The case study group was matched to a control group that was composed of patients who received salvage systemic chemotherapy (intravenous platinum plus intravenous paclitaxel) in a 1:2 ratio. The overall survival was compared between the case group and the control group, and the IP treatment-related toxicities were reported.

Results: In total, 11 patients were assigned into the case group and 22 patients were assigned into the control group. The median overall survival (95\% confidence interval) was 40.5 (25.5-56.2) months for the case group versus 28.0 (18.0-37.0) for the control group (hazard ratio $=0.37$ (95\% confidence interval, $0.15-0.95) ; \mathrm{p}=0.032$, by the log-rank test). The most commonly observed toxicity was of gastrointestinal origin (81.8\%). Toxicities that stemmed from hematological, cardiovascular, neurological, and catheter-related complications were similar to results published in other studies on IP chemotherapy for ovarian cancer.

Conclusion: Salvage IP chemotherapy may potentially confer a longer overall survival than conventional systemic chemotherapy in the treatment of relapsed type II endometrial cancer. (J Turk Ger Gynecol Assoc 2016; 17: 176-81)
\end{abstract}

Keywords: Intraperitoneal chemotherapy, type II endometrial cancer, overall survival

Received: 4 May, 2016 Accepted: 3 September, 2016

\section{Introduction}

Type II endometrial cancer with clear cell or papillary serous histology exhibits distinct biological behavior from type I endometrial cancer (1). This specific disease accounts for only $10 \%$ of all endometrial cancer cases, but analysis of historical data has shown a propensity for early extrauterine tumor spreading and a worse prognosis $(2,3)$. To date, randomized trials for this specific type of cancer are very rare due to the relatively low disease incidence. As such, published studies of adjuvant therapy are mainly extracted from heterogeneously treated patients $(4,5)$.

Currently, the standard front-line treatment for type II endometrial cancer includes surgical staging (or maximal debulking for the gross disease) and adjuvant chemotherapy, which is similar to the treatment for epithelial ovarian cancer. However, although treatment mechanisms for relapsed epithelial ovarian cancer have been well established, specific treatment for relapsed type II endometrial carcinoma has yet to be defined due to the lack of randomized trials for this relatively rare disease $(6,7)$.

The role of intraperitoneal (IP) chemotherapy in the treatment of epithelial ovarian cancer has been well established from published randomized trials (8-10). Nevertheless, three ongoing large-scale randomized trials are being conducted to examine the efficacy of carboplatin-based IP chemotherapy in the treatment of epithelial ovarian cancer $(11,12)$. In contrast, only one study of IP chemotherapy as a front-line therapy for type II endometrial cancer has been published thus far (13). Moreover, to the best of our knowledge, the role of salvage IP chemotherapy for relapsed type II endometrial cancer has yet to be elucidated.

In this work, we conducted a case-control study to evaluate the role of salvage IP chemotherapy for relapsed type II endometrial cancer. Eleven patients who were diagnosed with relapsed type II endometrial cancer were presented with peritoneal spread and received salvage IP chemotherapy after secondary cytoreductive surgery; these patients constituted 
the case group. Concurrently, twenty-two patients with the same diagnosis who received salvage systemic chemotherapy, constituted the control group. Both overall survival and instantaneous hazard function were compared between the case group and the control group. Additionally, IP treatment-related toxicities were detailed.

\section{Material and Methods}

\section{Study population}

This study entailed a retrospective analysis of prospectively collected data from an electronic health care database. Data was obtained from consecutive patients who were diagnosed with relapsed type II endometrial cancer between January 2000 and December 2012. These patients also underwent secondary cytoreductive surgery for a residual tumor less than $1 \mathrm{~cm}$. Selection criteria for secondary cytoreductive surgery must meet either of the following two criteria: (1) solitary tumor recurrence and (2) diffuse intraperitoneal spreading without evidence of bowel obstruction.

We selected patients who received salvage IP chemotherapy to serve as the case group. Accordingly, each patient in the case group was matched 1:2 to the control group, which was defined as patients who received salvage intravenous chemotherapy after secondary cytoreductive surgery for a residual tumor less than $1 \mathrm{~cm}$.

The institutional review board of Taipei Veterans General Hospital, Taiwan approved the current study. The procedures used in this study were conducted in accordance with the guidelines of the Declaration of Helsinki as it pertains to human subject experimentation (14).

\section{Definition of secondary cytoreductive surgery}

After a panel discussion that involved multidisciplinary care providers, once secondary cytoreductive surgery was considered appropriate for patients diagnosed with a relapsed disease; they were informed about the possibility of a secondary cytoreductive surgery. In cases when operation of the stomach, bowel, liver, diaphragm, spleen, or pancreas were seemingly necessary, consultation with an expert in the field of general surgery was issued in advance. If the patient had undergone an ostomy procedure, then a specific care team was consulted for wound care service and ostomy education.

Surgery that was performed only to relieve symptoms (e.g., relief of bowel obstruction) and performed strictly for palliative purposes (e.g., abscess drainage) or surgery within the context of primary therapy (e.g., second-look laparotomy or interval cytoreductive surgery) were excluded from the definition of secondary cytoreductive surgery.

Definition of salvage chemotherapy for the case group and the control group

The dosing schedules for the case group included IP delivery of a platinum (cisplatin (Abiplatin ${ }^{\circledR}$; TEVA pharmaceutical, Petah Tikva, Israel) or carboplatin (Paraplatin ${ }^{\circledR}$; Bristol-Myers Squibb Co, Princeton, NJ, USA) agent. Dosing of cisplatin $\left(100 \mathrm{mg} / \mathrm{m}^{2}\right)$ or carboplatin (either AUC 5 or 6$)$ occurred in
$2 \mathrm{~L}$ of normal saline. This agent was administered via Tenckhoff catheters that were implanted during the secondary cytoreductive surgery. Concurrently, intravenous delivery of paclitaxel (Taxol ${ }^{\circledR}$, Bristol-Myers Squibb Co.; Princeton, NJ, USA) dosing at $175 \mathrm{mg} / \mathrm{m}^{2}$ was administered the same day. In summary, the case group received IP platinum plus intravenous paclitaxel.

The dosing schedule for the control group consisted of intravenous delivery of a platinum agent, dosing at cisplatin (100 $\mathrm{mg} / \mathrm{m}^{2}$ ) or carboplatin (either AUC 5 or 6 ), plus the intravenous delivery of paclitaxel $\left(175 \mathrm{mg} / \mathrm{m}^{2}\right)$ on the same day. In summary, the control group received intravenous platinum plus intravenous paclitaxel.

The dosing schedules for both the case group (i.e., salvage IP chemotherapy) and the control group (i.e., salvage systemic chemotherapy) were repeated every three weeks for a total of six assigned cycles, provided that the serum creatinine concentration was less than or equal to $2.0 \mathrm{mg} / \mathrm{dL}$, the white-cell count was higher than $3,000 / \mathrm{mm}^{3}$, and the platelet count was higher than $80,000 / \mathrm{mm}^{3}$.

\section{Safety evaluation}

The effects of treatment-related toxicities were evaluated according to the National Cancer Institute Common Terminology Criteria for Adverse Events (NCI-CTCAE v4.0; http://ctep.cancer. gov/). Toxicity profiles, such as fever for more than 3 days, as well as hematological, cardiovascular, renal, and neurological profiles were recorded. In addition, IP catheter-related complications, including infection and obstruction, were also measured during the courses of treatment.

\section{Statistical analysis}

Continuous variables are presented as the mean ( \pm standard deviations) and were compared using the Student's unpaired t-test. Categorical variables are presented as counts and percentages and were compared using the $\chi^{2}$ test when appropriate (expected frequency $>5$ ). Tumor response was evaluated at 1 month after completion of chemotherapy using the RECIST criteria, version 1.1 (15). Overall survival is defined from the date of the first diagnosis to the date of the last follow-up or death. The date of last follow-up was set as December 31, 2015. An analysis of survival was conducted using the Kaplan-Meier method, and the survival of each group was compared using the log-rank test. Moreover, the hazard function, which is also called the instantaneous failure rate and force of mortality, was plotted for both the case group and the control group (16).

All analyses were performed using STATA SE version 12 (Stata Corp.; College Station, Texas, USA), and $\mathrm{p}<0.05$ was considered statistically significant.

\section{Results}

Figure 1 depicts the process of case selection and matching. Initially, ninety-seven patients were identified. After the first round of screening, patients who met the defined criteria, 


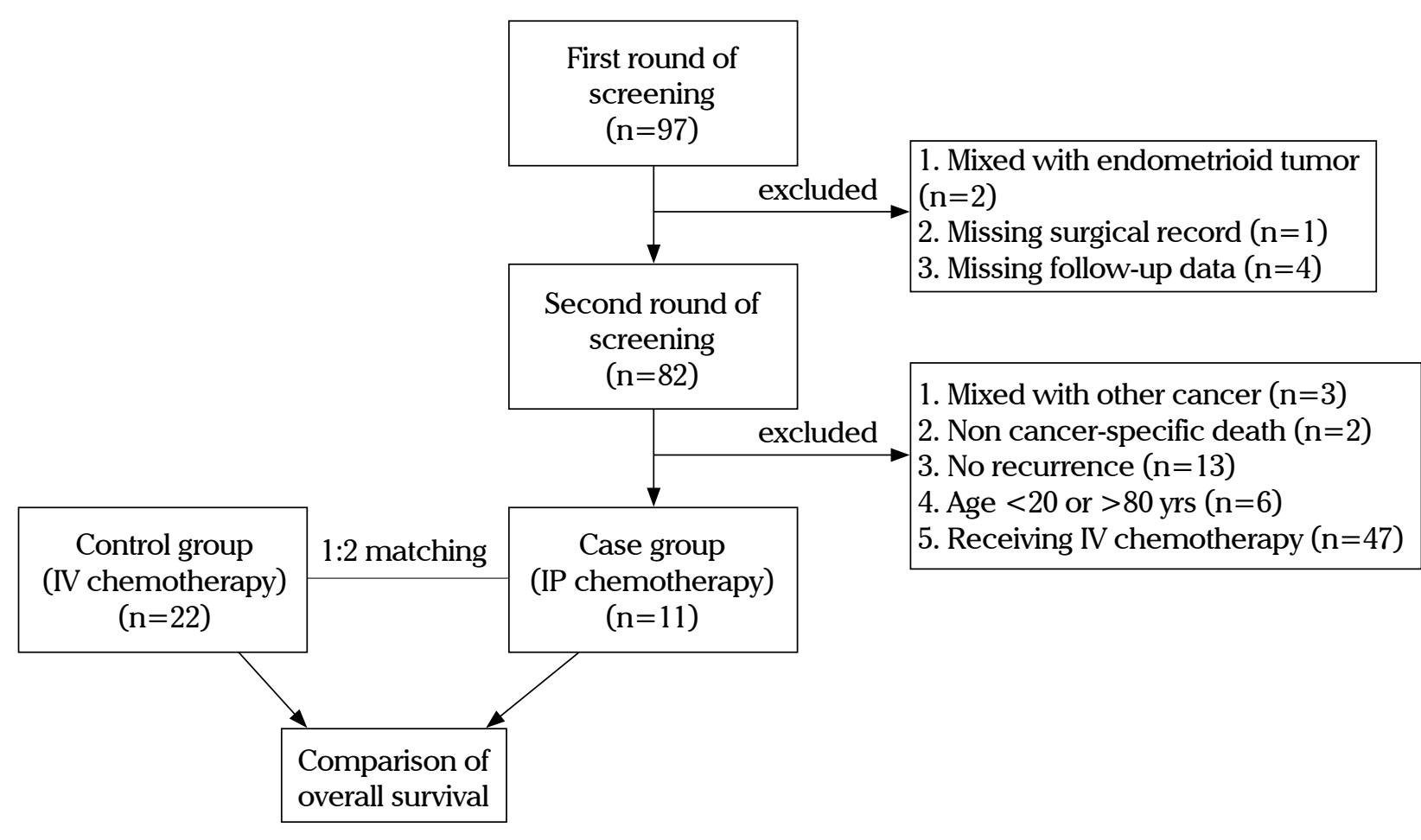

Figure 1. Flow chart describing the screening process of included patients

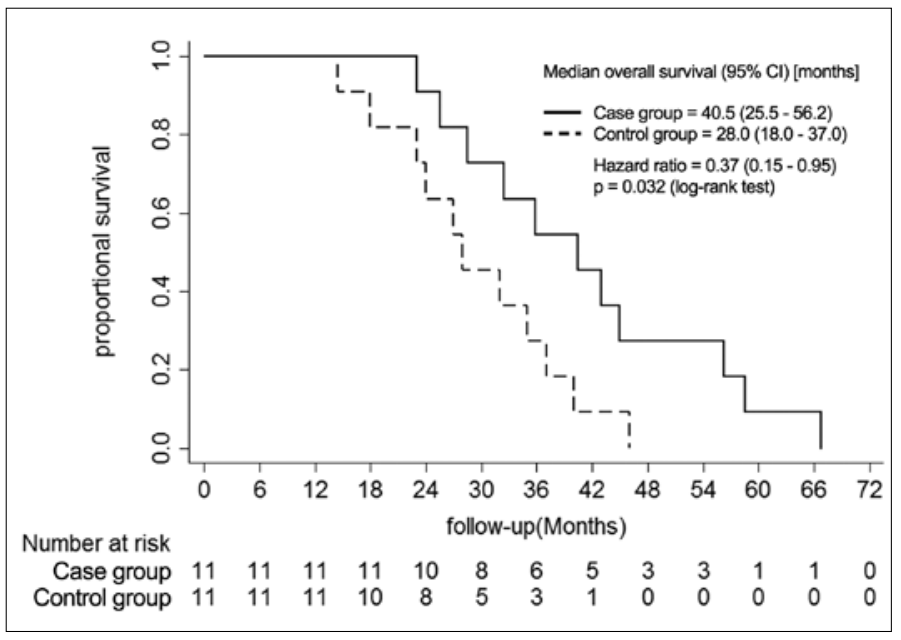

Figure 2. Kaplan-Meier overall survival for the case group (IP therapy) and the control group (systemic therapy)

including those with mixed tumors of endometrioid histology $(n=12)$, missing surgical records $(n=1)$, and missing follow-up data $(n=4)$, were excluded. The remaining patients $(n=82)$ then entered a second round of screening. Those who met the following defined criteria were also excluded: those with other cancers $(n=3)$, non-cancer specific deaths $(n=2)$, no recurrence $(n=13)$, age $<20$ or $>80$ years, and treatment with systemic chemotherapy $(n=47)$. The remaining patients formed the case group, which consisted of patients who were diagnosed with relapsed type II endometrial cancer and who had residual tumors less than $1 \mathrm{~cm}$ in diameter; these patients received IP chemotherapy after secondary cytoreductive surgery. The case group was 1:2 matched to the control group, which consisted of patients who were diagnosed with relapsed type II endometrial cancer and who had residual tumors less than $1 \mathrm{~cm}$ in diameter; these patients received systemic chemotherapy after secondary cytoreductive surgery.

Table 1 outlines the demographics and clinical characteristics of the recruited patients $(n=11)$ who received salvage IP chemotherapy. Among these, nine patients (81.8\%) were diagnosed with serous carcinoma, while the remaining two patients were diagnosed with the clear cell subtype. A total of seven patients (63.6\%) completed the six assigned IP cycles. Most of the reasons for the discontinuation of IP chemotherapy were due to catheter obstruction.

Next, a Kaplan-Meier overall survival curve was constructed for the case group and the control group. The median overall survival (95\% confidence interval) was 40.5 (25.5-56.2) months for the case group versus 28.0 (18.0-37.0) for the control group [hazard ratio $=0.37(0.15-0.95) ; \mathrm{p}=0.032$, by the log-rank test] (Figure 2).

Figure 3 presents the hazard function for both the case control groups. The hazard rate shows a significantly higher and steeper curve, which implies that patients in the control group always faced a higher instantaneous risk of death than the case group during the entire follow-up.

Lastly, grade 3 or 4 toxicities during IP chemotherapy were tabulated (Table 2). The most commonly observed toxicity was of gastrointestinal origin (81.8\%). Toxicities that involved hematological, cardiovascular, neurological, and catheterrelated complications were not different from those that were 
Table 1. Baseline demographics and clinical characteristics of patients receiving salvage IP chemotherapy $(n=11)$

\begin{tabular}{|c|c|c|c|c|c|c|c|c|}
\hline $\begin{array}{l}\text { Case } \\
\text { No. }\end{array}$ & Age & Histology & $\begin{array}{c}\text { ECOG } \\
\text { performance } \\
\text { score }\end{array}$ & Tumor location & $\begin{array}{l}\text { Presenting } \\
\text { symptoms }\end{array}$ & $\begin{array}{c}\text { Completed } \\
\text { cycles }\end{array}$ & $\begin{array}{c}\text { Reason for } \\
\text { discontinuation }\end{array}$ & $\begin{array}{l}\text { Tumor } \\
\text { response }\end{array}$ \\
\hline 1 & 54 & Serous & 1 & Peritoneal spreading & Ascites & 6 & NA & Partial \\
\hline 2 & 61 & Serous & 0 & Bowel, unspecified & Fatigue & 6 & $\mathrm{NA}$ & Partial \\
\hline 3 & 53 & Serous & 1 & Peritoneal spreading & Bloating sensation & 6 & $\mathrm{NA}$ & Complete \\
\hline 4 & 66 & Clear cell & 0 & Peritoneal spreading & Ascites & 4 & $\begin{array}{l}\text { Catheter } \\
\text { obstruction }\end{array}$ & Stable \\
\hline 5 & 59 & Serous & 1 & Spleen metastases & Poor appetite & 6 & NA & Partial \\
\hline 6 & 71 & Serous & 2 & $\begin{array}{c}\text { Peritoneal + liver surface } \\
\text { spreading }\end{array}$ & Bloating sensation & 3 & $\begin{array}{l}\text { Catheter } \\
\text { obstruction }\end{array}$ & Stable \\
\hline 7 & 67 & Clear cell & 1 & Peritoneal spreading & Ascites & 6 & NA & Progressed \\
\hline 8 & 75 & Serous & 1 & Peritoneal spreading & Ascites & 6 & NA & Stable \\
\hline 9 & 64 & Serous & 1 & Sigmoid colon + small bowel & Bloating sensation & 6 & NA & Partial \\
\hline 10 & 71 & Serous & 1 & Peritoneal spreading & Bloating sensation & 4 & $\begin{array}{l}\text { Catheter } \\
\text { obstruction }\end{array}$ & Stable \\
\hline 11 & 62 & Serous & 0 & Bowel, unspecified & Ascites & 5 & $\begin{array}{c}\text { Catheter-induced } \\
\text { infection }\end{array}$ & Complete \\
\hline
\end{tabular}

Table 2. Patients experiencing grade 3 and 4 toxicity during IP chemotherapy $(n=11)$

\begin{tabular}{|l|c|c|c|}
\hline & Grade 3 & Grade 4 & Overall \\
\hline Treatment-related fever & 0 & 0 & $0(0 \%)$ \\
\hline Neutrophil count & 3 & 1 & $4(36.4 \%)$ \\
\hline Anemia & 1 & 0 & $1(9.1 \%)$ \\
\hline Platelet & 2 & 0 & $2(18.2 \%)$ \\
\hline Gastrointestinal & 8 & 1 & $9(81.8 \%)$ \\
\hline Cardiovascular & 1 & 0 & $1(9.1 \%)$ \\
\hline Neurologic & 4 & 1 & $5(45.5 \%)$ \\
\hline Renal & 1 & 0 & $1(9.1 \%)$ \\
\hline Catheter-related infection & NA & NA & $2(18.2 \%)$ \\
\hline Catheter obstruction & NA & NA & $1(9.1 \%)$ \\
\hline IP: intraperitoneal; NA: not applicable & \\
\hline
\end{tabular}

published in reports of IP chemotherapy for ovarian cancer (8-10).

\section{Discussion}

In the current matched case-control study, we aimed to analyze the efficacy of salvage IP chemotherapy for the treatment of relapsed type II endometrial cancer. Our data was in agreement with the results of published randomized trials of IP chemotherapy for ovarian cancer, and show that salvage IP chemotherapy yields a significantly longer overall survival than salvage

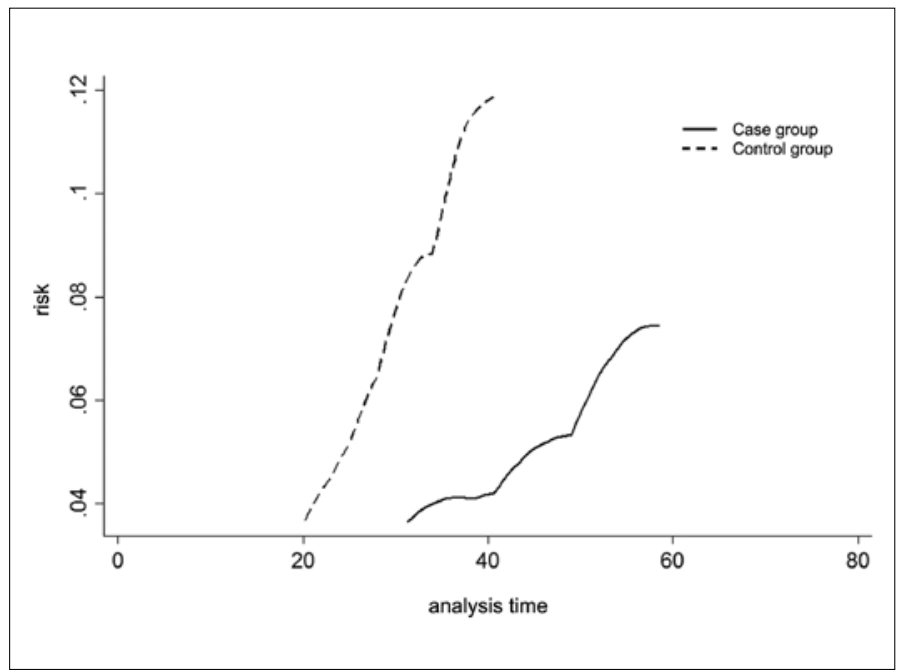

Figure 3. Hazard curve for the case group (IP therapy) and the control group (systemic therapy)

systemic chemotherapy. Furthermore, the completion rate for the six assigned IP cycles $(7 / 11,63.6 \%)$ and the toxicity profiles were comparable to those in published IP randomized trials for ovarian cancer. Taken together, salvage IP chemotherapy is worthy of consideration as a potential novel therapy for patients with relapsed type II endometrial cancer.

Uterine clear cell carcinoma and uterine papillary serous carcinoma are subtypes of type II endometrial cancer that show aggressive biological behavior and a predilection for deep myometrial invasion, lympho-vascular space invasion, and a propensity for peritoneal spreading (17-19). Additionally, in the setting of relapsed type II endometrial cancer, peritoneal 
spreading is the major presenting symptom in the majority of involved cases $(18,20)$. Thus, the peritoneal cavity provides a sanctuary site for the development of local therapies (i.e., IP chemotherapy).

Currently, no specific tailored treatment exists for relapsed type II endometrial cancer due to the rarity of this disease. Still, the current gold standard treatment for relapsed type II endometrial cancer is the same as that for relapsed type I endometrial cancer, which is based on a series of published phase III randomized trials that focused on the efficacy of chemotherapy $(7,21-25)$. However, given the apparent differences in clinical behavior between type I and type II endometrial cancers, it has been suggested that treatments should be tailored according to the histologic type. To date, potential chemotherapy regimens for relapsed type II endometrial cancer include cisplatin, cyclophosphamide, topotecan, doxorubicin, and pegylated liposomal doxorubicin (26). Furthermore, patients with relapsed type II endometrial cancer are unlikely to be successfully treated with surgery or radiation as salvage treatments, and demonstrate a less favorable response rate to chemotherapy than patients with endometrioid cancer (27). As such, the development of novel treatment modalities for relapsed type II endometrial cancer is imperative.

In addition to the established role of IP chemotherapy in the treatment of epithelial ovarian cancer, according to published randomized trials, IP chemotherapy even shows long-term survival benefits that extend beyond 10 years. The long-term survival benefits may encourage more clinicians to adopt IP chemotherapy in their communities (28). Nonetheless, according to a recent report, the adoption of IP chemotherapy is an underused strategy for eligible patients in general, and the integration of IP chemotherapy into clinical practice varies significantly among institutions (29). Thus, the implementation of IP chemotherapy merits further education and encouragement for gynecologic oncologists.

The current study has two primary advantages. First, the current study adopted IP delivery of platinum plus intravenous delivery of paclitaxel, whereas a previous study adopted IP delivery of platinum plus intravenous delivery of doxorubicin and cyclophosphamide (13). Apparently, the regimen used in the current study is favorable with respect to modern practices for endometrial cancer treatment. Second, aside from epithelial ovarian cancer, the current study found that IP chemotherapy is potentially feasible and useful in the treatment of relapsed type II endometrial cancer.

Some limitations of our study should be emphasized. First, we acknowledge the lack of some important patient-level information in the current work. For example, socioeconomic factor has been linked to cancer mortality, and the lack of this information may lead to biased results (30). Second, follow-up protocols after secondary cytoreductive surgery were not strictly defined (e.g., frequency of image study), which means that the exact timing of the relapse was in doubt. Third, because the current study is essentially a retrospective study, many factors relevant in the front-line treatment setting were not as strictly controlled as for those in a randomized trial. As such, the results of overall survival may have been prone to major bias. Lastly, the sample size in the platinum-refractory/resistant group is relatively small, which may have affected the validity of the conclusion.
In conclusion, this matched case-control study reveals that salvage IP chemotherapy may potentially confer longer overall survival than conventional systemic chemotherapy in the treatment of relapsed type II endometrial cancer. Moreover, salvage IP chemotherapy is associated with comparable IP-related toxicities compared with those of previously published randomized trials for epithelial ovarian cancer. This study may widen the application of IP chemotherapy, but a prospective study with an adequate sample size is still needed to validate its application.

Ethics Committee Approval: Ethics committee approval was received for this study from the ethics committee of Taipei Veterans General Hospital. / IRB No. 2016-05-004CC.

\section{Informed Consent: $N / A$.}

Peer-review: Externally peer-reviewed.

Author Contributions: Concept - Y.C.T., C.M.C.; Design - Y.C.T., Y.H.C., C.M.C.; Supervision - C.M.C.; Resources - Y.C.T., Y.H.C., Y.C., C.M.C.; Data Collection and/or Processing - Y.C.T., Y.H.C., C.M.C.; Analysis and/or Interpretation - Y.C.T., Y.H.C., C.M.C.; Literature Search - Y.C.T.; Writing Manuscript - Y.C.T., Y.H.C., Y.C., C.M.C.; Critical Review - Y.C.T., Y.H.C., Y.C., C.M.C.

Acknowledgements: The authors would like to thank the Task Force on Excellence on Intraperitoneal Chemotherapy Research group, Lilly Wen, MD (Catholic Cardinal Tien Hospital, Taipei), and Kuo-Chang Wen, MD, Chih-Yu Chen, MD, Peng-Hui Wang, MD, Nae-Fong Twu, MD, and Hsiang-Tai Chao, MD (Taipei Veterans General Hospital).

Conflict of Interest: No conflict of interest was declared by the authors.

Financial Disclosure: The authors declared that this study has partially supported by the National Science Council, Taiwan (No. NSC 104-NU-E010-004-NU \& MOST 103-2410-H-264-004).

Yi-Chen Tsai and Yen-Hou Chang contributed equally to this study.

\section{References}

1. Mendivil A, Schuler KM, Gehrig PA. Non-endometrioid adenocarcinoma of the uterine corpus: a review of selected histological subtypes. Cancer Control 2009; 16: 46-52.

2. Boruta DM 2nd, Gehrig PA, Fader AN, Olawaiye AB. Management of women with uterine papillary serous cancer: a Society of Gynecologic Oncology (SGO) review. Gynecol Oncol 2009; 115: 142-53.

3. Greggi S, Mangili G, Scaffa C, Scala F, Losito S, Iodice F, et al. Uterine papillary serous, clear cell, and poorly differentiated endometrioid carcinomas: a comparative study. Int J Gynecol Cancer 2011; 21: 661-7.

4. Fields AL, Einstein MH, Novetsky AP, Gebb J, Goldberg GL. Pilot phase II trial of radiation "sandwiched" between combination paclitaxel/platinum chemotherapy in patients with uterine papillary serous carcinoma (UPSC). Gynecol Oncol 2008; 108: 201-6.

5. Johnson N, Bryant A, Miles T, Hogberg T, Cornes P. Adjuvant chemotherapy for endometrial cancer after hysterectomy. Cochrane Database Syst Rev 2011: CD003175.

6. Network NCC. NCCN Clinical Practice Guidelines in Oncology: Ovarian Cancer Version 22015 [cited 2015 December 1]. Available from: http://www.nccn.org/professionals/physician_gls/f_guidelines.asp.

7. Network NCC. NCCN Clinical Practice Guidelines in Oncology: Uterine Cancers Version 12015 [cited 2015 December 1]. Available from: http://www.nccn.org/professionals/physician_gls/f_guidelines.asp. 
8. Alberts DS, Liu PY, Hannigan EV, O’Toole R, Williams SD, Young JA, et al. Intraperitoneal cisplatin plus intravenous cyclophosphamide versus intravenous cisplatin plus intravenous cyclophosphamide for stage III ovarian cancer. N Engl J Med 1996; 335: 1950-5.

9. Markman M, Bundy BN, Alberts DS, Fowler JM, Clark-Pearson DL, Carson LF, et al. Phase III trial of standard-dose intravenous cisplatin plus paclitaxel versus moderately high-dose carboplatin followed by intravenous paclitaxel and intraperitoneal cisplatin in small-volume stage III ovarian carcinoma: an intergroup study of the Gynecologic Oncology Group, Southwestern Oncology Group, and Eastern Cooperative Oncology Group. J Clin Oncol 2001; 19: 1001-7.

10. Armstrong DK, Bundy B, Wenzel L, Huang HQ, Baergen R, Lele S, et al; Gynecologic Oncology Group. Intraperitoneal cisplatin and paclitaxel in ovarian cancer. N Engl J Med 2006; 354: 34-43.

11. Gadducci A, Conte PF. Intraperitoneal chemotherapy in the management of patients with advanced epithelial ovarian cancer: a critical review of the literature. Int J Gynecol Cancer 2008; 18: 94353.

12. Fujiwara K. Three ongoing intraperitoneal chemotherapy trials in ovarian cancer. J Gynecol Oncol 2012; 23: 75-7.

13. Chambers JT, Chambers SK, Kohorn EI, Carcangiu ML, Schwartz PE. Uterine papillary serous carcinoma treated with intraperitoneal cisplatin and intravenous doxorubicin and cyclophosphamide. Gynecol Oncol 1996; 60: 438-42.

14. Association WM. Declaration of Helsinki [cited 2003 November 5]. Available from: http://www.wma.net/e/ethicsunit.

15. Nishino M, Jagannathan JP, Ramaiya NH, Van den Abbeele. Revised recist guideline version 1.1: What oncologists want to know and what radiologists need to know. AJR Am J Roentgenol 2010; 195: 281-9.

16. Bradburn MJ, Clark TG, Love SB, Altman DG. Survival analysis part II: multivariate data analysis--an introduction to concepts and methods. Br J Cancer 2003; 89: 431-6.

17. Lindahl B, Persson J, Ranstam J, Willén R. Long-term survival in uterine clear cell carcinoma and uterine papillary serous carcinoma. Anticancer Res 2010; 30: 3727-30.

18. Murphy KT, Rotmensch J, Yamada SD, Mundt AJ. Outcome and patterns of failure in pathologic stages I-IV clear-cell carcinoma of the endometrium: implications for adjuvant radiation therapy. Int J Radiat Oncol Biol Phys 2003; 55: 1272-6.

19. Tay EH, Ward BG. The treatment of uterine papillary serous carcinoma (UPSC): are we doing the right thing? Int J Gynecol Cancer 1999; 9: 463-9.

20. Sood BM, Jones J, Gupta S, Khabele D, Guha C, Runowicz C, et al. Patterns of failure after the multimodality treatment of uterine papillary serous carcinoma. Int J Radiat Oncol Biol Phys 2003; 57: 208-16.

21. Fleming GF, Brunetto VL, Cella D, Look KY, Reid GC, Munkarah AR, et al. Phase III trial of doxorubicin plus cisplatin with or without paclitaxel plus filgrastim in advanced endometrial carcinoma: a Gynecologic Oncology Group Study. J Clin Oncol 2004; 22: 2159-66.

22. Fleming GF, Filiaci VL, Bentley RC, Herzog T, Sorosky J, Vaccarello $\mathrm{L}$, et al. Phase III randomized trial of doxorubicin + cisplatin versus doxorubicin +24 -h paclitaxel + filgrastim in endometrial carcinoma: a Gynecologic Oncology Group study. Ann Oncol 2004; 15 : 1173-8.

23. Gallion HH, Brunetto VL, Cibull M, Lentz SS, Reid G, Soper JT, et al. Randomized phase III trial of standard timed doxorubicin plus cisplatin versus circadian timed doxorubicin plus cisplatin in stage III and IV or recurrent endometrial carcinoma: a Gynecologic Oncology Group Study. J Clin Oncol 2003; 21: 3808-13.

24. Thigpen JT, Brady MF, Homesley HD, Malfetano J, DuBeshter B, Burger RA, et al. Phase III trial of doxorubicin with or without cisplatin in advanced endometrial carcinoma: a gynecologic oncology group study. J Clin Oncol 2004; 22: 3902-8.

25. Homesley HD, Filiaci V, Gibbons SK, Long HJ, Cella D, Spirtos NM, et al. A randomized phase III trial in advanced endometrial carcinoma of surgery and volume directed radiation followed by cisplatin and doxorubicin with or without paclitaxel: A Gynecologic Oncology Group study. Gynecol Oncol 2009; 112: 543-52.

26. Muggia FM, Blessing JA, Sorosky J, Reid GC. Phase II trial of the pegylated liposomal doxorubicin in previously treated metastatic endometrial cancer: a Gynecologic Oncology Group study. J Clin Oncol 2002; 20: 2360-4.

27. McMeekin DS, Filiaci VL, Thigpen JT, Gallion HH, Fleming GF, Rodgers $\mathrm{WH}$, et al. The relationship between histology and outcome in advanced and recurrent endometrial cancer patients participating in first-line chemotherapy trials: a Gynecologic Oncology Group study. Gynecol Oncol 2007; 106: 16-22.

28. Tewari D, Java JJ, Salani R, Armstrong DK, Markman M, Herzog T, et al. Long-term survival advantage and prognostic factors associated with intraperitoneal chemotherapy treatment in advanced ovarian cancer: a gynecologic oncology group study. J Clin Oncol 2015; 33 : 1460-6.

29. Wright AA, Cronin A, Milne DE, Bookman MA, Burger RA, Cohn DE, et al. Use and Effectiveness of Intraperitoneal Chemotherapy for Treatment of Ovarian Cancer. J Clin Oncol 2015; 33: 2841-7.

30. Albano JD, Ward E, Jemal A, Anderson R, Cokkinides VE, Murray T, et al. Cancer mortality in the United States by education level and race. J Natl Cancer Inst 2007; 99: 1384-94. 